\title{
Emerging disease-modifying therapies for sickle cell disease
}

Haematologica 2019

Volume 104(9):1710-1719

\section{Correspondence:}

JANE LITTLE

jane_little@med.unc.edu

Received: April 10, 2019.

Accepted: July 10, 2019.

Pre-published: August 14, 2019.

doi:10.3324/haematol.2018.207357

Check the online version for the most updated information on this article, online supplements, and information on authorship \& disclosures: www.haematologica.org/content/104/9/1710

\section{(C)2019 Ferrata Storti Foundation}

Material published in Haematologica is covered by copyright. All rights are reserved to the Ferrata Storti Foundation. Use of published material is allowed under the following terms and conditions:

https://creativecommons.org/licenses/by-nc/4.0/legalcode. Copies of published material are allowed for personal or internal use. Sharing published material for non-commercial purposes is subject to the following conditions:

https://creativecommons.org//icenses/by-nc/4.0/legalcode, sect. 3. Reproducing and sharing published material for commercial purposes is not allowed without permission in writing from the publisher.

\section{Marcus A. Carden ${ }^{1,2}$ and Jane Little ${ }^{2}$}

${ }^{1}$ Department of Pediatrics, Division of Pediatric Hematology/Oncology, University of North Carolina Chapel Hill School of Medicine and ${ }^{2}$ Department of Medicine, Division of Hematology, University of North Carolina Chapel Hill School of Medicine, Chapel Hill, NC, USA

\section{ABSTRACT}

S ickle cell disease afflicts millions of people worldwide and approximately 100,000 Americans. Complications are myriad and arise as a result of complex pathological pathways 'downstream' to a point mutation in DNA, and include red blood cell membrane damage, inflammation, chronic hemolytic anemia with episodic vaso-occlusion, ischemia and pain, and ultimately risk of cumulative organ damage with reduced lifespan of affected individuals. The National Heart, Lung, and Blood Institute's 2014 evidence-based guideline for sickle cell disease management states that additional research is needed before investigational curative therapies will be widely available to most patients with sickle cell disease. To date, sickle cell disease has been cured by hematopoietic stem cell transplantation in approximately 1,000 people, most of whom were children, and significantly ameliorated by gene therapy in a handful of subjects who have only limited follow-up thus far. During a timespan in which over 20 agents were approved for the treatment of cystic fibrosis by the Food and Drug Administration, similar approval was granted for only two drugs for sickle cell disease (hydroxyurea and L-glutamine) despite the higher prevalence of sickle cell disease. This trajectory appears to be changing, as the lack of multimodal agent therapy in sickle cell disease has spurred engagement among many in academia and industry who, in the last decade, have developed new drugs poised to prevent complications and alleviate suffering. Identified therapeutic strategies include fetal hemoglobin induction, inhibition of intracellular $\mathrm{HbS}$ polymerization, inhibition of oxidant stress and inflammation, and perturbation of the activation of the endothelium and other blood components (e.g. platelets, white blood cells, coagulation proteins) involved in the pathophysiology of sickle cell disease. In this article, we present a crash-course review of disease-modifying approaches (minus hematopoietic stem cell transplant and gene therapy) for patients with sickle cell disease currently, or recently, tested in clinical trials in the era following approval of hydroxyurea.

\section{Introduction}

As the most common monogenic disorder and first defined 'molecular' disease, ${ }^{1,2}$ sickle cell disease (SCD) comprises a complex group of hematologic disorders that share a common genetic link - a missense mutation in the seventh codon of the $\beta$ globin gene that leads to adenine being replaced with thymine (GAG $\rightarrow G T G$ ). In turn, at the sixth position of the mature peptide of the $\beta$-globin protein the amino acid valine replaces glutamic acid ${ }^{3}$ which, when inherited in the homozygous state, results in erythroid precursors and mature sickle red blood cells (RBC) that contain abnormal sickle hemoglobin ( $\mathrm{HbS}: \alpha_{2} \beta \mathrm{S}_{2}$ ), rather than normal adult hemoglobin $\left(\mathrm{HbA}: \alpha_{2} \beta_{2}\right)$. Compound heterozygous diseases (HbSC: $\alpha^{2} \beta^{\mathrm{s}} \beta^{\mathrm{c}}$; and $\mathrm{HbS}^{+}$thalassemia: $\alpha_{2} \beta^{s} \beta^{+- \text {Thal) }}$ have milder features overall, but can be debilitating and highly morbid as well. Under deoxygenated conditions, HbS polymerizes intracellularly, 
which makes the sickle RBC fragile, less deformable, and dehydrated, and subsequently more susceptible to endothelial adhesion through activation of adhesion receptors..$^{4.7}$ Downstream consequences include microvascular occlusion, leukocyte and platelet activation, and a pathologically altered endothelium all existing in a proinflammatory and pro-thrombophilic plasma milieu. ${ }^{8-13}$ The biomechanical properties of sickle RBC are dependent on intrinsic factors, such as the composition of the hemoglobin [e.g., presence of the anti-sickling fetal hemoglobin $\left(\mathrm{HbF}: \alpha_{2} \gamma_{2}\right)$ ], membrane integrity, cellular volume and hydration, cytosolic make-up, and extrinsic factors, such as inflammatory cytokines, activated endothelium, and other blood components including platelets, leukocytes, and proteins involved in coagulation. ${ }^{8}$ Clinical manifestations of the presence of $\mathrm{HbS}$ polymerization are wide-ranging and include chronic hemolytic anemia, episodic microcirculatory vaso-occlusion with tissue ischemia and pain, and ultimately chronic end-organ damage that can reduce the lifespan of an individual with SCD. ${ }^{14}$

Due to its impact on morbidity and mortality, SCD is increasingly being recognized as a global health problem. Researchers in academia and industry have reinvigorated efforts to cure patients with SCD; and where that is not possible because of medical and socioeconomic barriers they aim to prevent, delay, and mitigate its protean complications. ${ }^{15-17}$ Curing SCD through stem cell transplantation and achieving durable responses through gene therapy have become realities for some patients. ${ }^{18,19}$ However, as stated by the 2014 evidence-based guidelines from the National Heart, Lung, and Blood Institute (NHLBI), additional research is needed before potentially curative therapies are widely, safely, and inexpensively available to most patients. ${ }^{20}$ Therefore, in the era following approval of hydroxyurea by the United States Food and Drug Administration (FDA), providers will need to rely on improving patients' outcomes through utilization of one or more additional emerging novel therapies and advances in care. Although the economic cost benefit of such an approach is difficult to predict, conceptually this may evolve into a multi-faceted approach to SCD that is similar to that seen with multi-agent chemotherapy for the successful management of cancer. ${ }^{21}$

In this context, we present emerging non-genetic approaches (i.e. those that do not involve stem cell or gene therapy) currently or recently in clinical trials that offer innovative treatment and palliation in SCD. While we do include agents involved in epigenetic targeting, excellent reviews of other genetic approaches for disease modification or cure (i.e. those receiving stem cell transplants or gene therapy through gene addition, correction, or editing) can be found elsewhere. ${ }^{19,22,23}$

\section{Methods}

Relevant literature was identified through various mechanisms, including using search terms 'sickle cell disease' and 'novel treatments' in MEDLINE, reviewing recent abstracts presented at the American Society of Hematology annual meetings, and examining recent, relevant reviews by others in the field. ${ }^{15-17,21,24-28}$ Trials actively recruiting pediatric or adult patients with SCD, and which included subjects aged 18 years or older, as of February 15, 2019 were also evaluated through ClinicalTrials.gov. Upon review of each result, we excluded those trials involving gene modification, including stem cell transplant, gene addition, correction, or editing. As we outline in Online Supplementary Tables $S 1$ and S2, we broke down what we thought were novel and important treatments into two groups - those characterized by targeting the abnormal $\mathrm{HbS}$ and damaged sickle RBC (i.e. intrinsic to the RBC, including formation of deoxy-HbS and its polymerization in a dehydrated sickle $\mathrm{RBC}$ ) (Figure 1) and those targeting sequelae downstream from the red cell (i.e. extrinsic to the RBC, including abnormal endothelial and cellular adhesion, vascular tone, other blood components, and inflammation) (Figure 2).
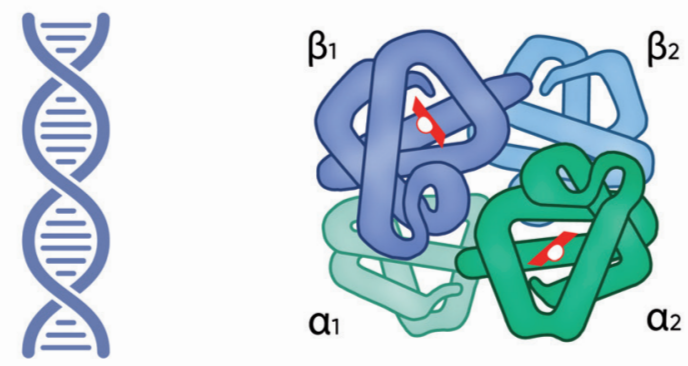

DNA
Hemoglobin
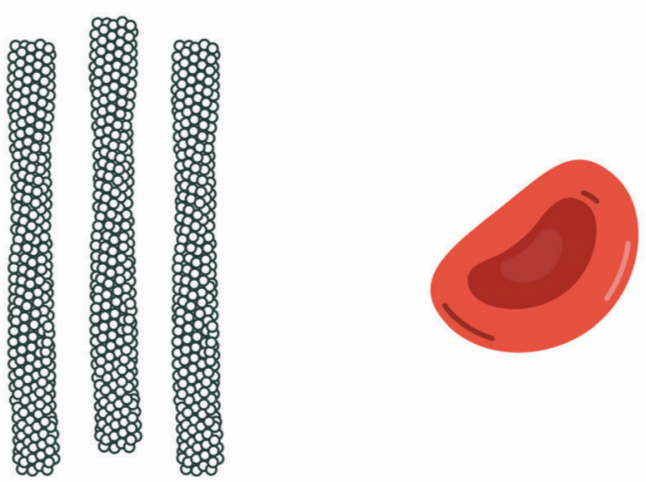
Deoxy-HbS polymer

Figure 1. Red cell intrinsic targets. The figure illustrates the therapeutic targets within the red cell precursor [DNA ${ }^{1}$, and the sickle red blood cell (RBC), HbS ${ }^{5}$, e.g. voxelator, and polymer formation ${ }^{16}$ ], which are most likely to modify sickle cell disease and to affect more than a single downstream sequelae (pain, inflammation, vasculopathy, so forth). RBC image: https://steemit.com/stemng/@gbindinazeez/sickle-cell-anaemia-an-endemic-disease-20181122t215228805z-post] 


\section{Red blood cell intrinsic targets}

The emerging disease-modifying approaches to SCD that target intrinsic characteristics of RBC are outlined in Online Supplementary Table S1 and discussed below.

\section{Targeting HbS polymerization through the induction of $\mathrm{HbF}$}

Several recently developed agents aim to reduce deoxy$\mathrm{HbS}$ polymerization, the root cause of SCD pathology, through delayed deoxygenation of $\mathrm{HbS}$, reduced intracellular $\mathrm{HbS}$ concentration (via cellular hydration), or induction of the anti-sickling $\mathrm{HbF}^{29}$ Hydroxyurea, a ribonucleotide reductase inhibitor with $\mathrm{HbF}$-inducing properties, is the paradigmatic HbF-inducing agent and was the first drug approved by the FDA for the treatment of adults and children with SCD. Hydroxyurea induces $\mathrm{HbF}$ and increases RBC volume, thereby reducing the likelihood of $\mathrm{HbS}$ polymerization. Hydroxyurea also decreases neutrophil and platelet counts and increases plasma nitric oxide levels, and is overall associated with decreased morbidity and improved mortality. ${ }^{30,31}$ The 2014 NHLBI guidelines state that hydroxyurea therapy should be initiated in adults with severe SCD, especially when quality of life is affected, and offered as a prophylactic treatment in young children with sickle cell anemia. ${ }^{20}$ Novel studies assessing the benefits of hydroxyurea are evaluating individualized pharmacokinetic-based dosing strategies (NCT03789591), the safety and feasibility of adding hydroxyurea to simple transfusions for stroke prevention (NCT03644953), and using patient navigators to reduce barriers to availability and non-adherence (NCT02197845).

However, some patients with SCD may not respond adequately to hydroxyurea or refuse treatment because of unwanted side-effects. As such, other agents that modify $\gamma$-globin gene silencing and induce $\mathrm{HbF}$ are being repurposed or newly investigated. Many drugs being, or previously, investigated work through novel epigenetic mecha- nisms within erythroid progenitors in the bone marrow. Decitabine with (NCT01685515) or without (NCT01375608) tetrahydrouridine (a cytidine deaminase inhibitor that prevents rapid deactivation of decitabine, thereby allowing the use of an oral formulation of this latter) is a chemotherapy used to treat myelodysplastic syndrome and acute myeloid leukemia. Decitabine and its historic antecedent 5-azacytidine inhibit DNA methyltransferase-1 (DNMT1), thereby reducing overall DNA methylation. ${ }^{32}$ Perturbed DNA methylation, in animal models and humans, appears to be the major mechanism for derepressed $\gamma$-globin expression arising from this class of agents. ${ }^{33}$ A phase I, first in-human trial of decitabine/tetrahydrouridine found this drug combination to be safe (without cytotoxicity or genotoxicity), well-tolerated, and effective, increasing $\mathrm{HbF}$ levels to $4-9 \%$, while doubling F-cell populations. ${ }^{34}$ Unlike 5-azacytidine, decitabine does not affect RNA metabolism and is likely to have an improved safety profile, although the impact of its irreversible incorporation into DNA has not been fully elucidated and long-term follow-up in large populations is not yet available.

Dimethyl butyrate (HOK-1001), an orally bioavailable short-chain fatty acid derivative and inhibitor of histone deacetylases, was active in animal models. However, a phase II double-blind placebo-controlled study (NCT01601340) was terminated early as the drug was associated with an insignificant rise in $\mathrm{HbF}$ and more pain episodes when compared to placebo..$^{35}$ Other histone deacetylase inhibitors that work in part by reversing $\gamma$-globin silencing and show promise in phase I trials in SCD include the multiple myeloma drugs panobinostat (NCT01245179) and pomalidomide (NCT01522547). ${ }^{36-38}$ Again, long-term risk-benefit analyses are not yet available.

Lysine-specific demethylase-1 (LSD1) is another enzyme and epigenetic target that modifies histones through demethylation in the process of $\gamma$-globin gene
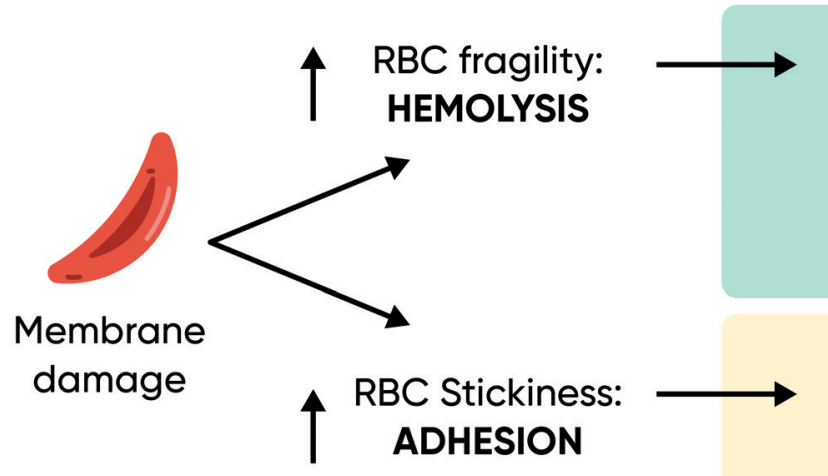

Cell-free $\mathrm{Hb}$ Plasma heme $\nabla$ NO<smiles>[3H][SiH3]</smiles>

Microvascular occlusion

$\nabla$
Abberrant vaso-regulation

Thrombophilia Infiammation Cellular activation Ischemia-reperfusion injury

Oxidant stress

Figure 2. Red cell extrinsic targets. The figures shows the therapeutic targets and pathways extrinsic to the red blood cell (RBC), which are most likely to be useful for managing sickle cell disease, palliating symptoms, and improving organ function. NO: nitric oxide. [RBC image: https://steemit.com/stemng/@gbindinazeez/sickle-cell-anaemia-an-endemic-disease-20181122t215228805z-post] 
silencing at the $\gamma$-promoter DRED complex, which also contains the demethylase DNMT1. LSD1 inhibition in $\mathrm{SCD}$ mice increases $\mathrm{HbF}$, reduces reticulocytosis, and decreases organ damage. ${ }^{39}$ A phase I open-label study (NCT03132324) evaluating the safety, pharmacokinetics, and biological activity of the LSD1 inhibitor INCB059872 in patients with SCD was terminated early due to a 'business decision' and the drug is being examined as a treatment for leukemia. Known for its glucose-lowering mechanism in patients with type 2 diabetes, metformin was recently shown to induce $\mathrm{HbF}$ in a FOXO3-dependent manner that was additive to hydroxyurea in vitro. ${ }^{40}$ Metformin is being investigated in a phase I, dose-escalation pilot study in SCD patients with or without the addition of hydroxyurea (NCT02981329).

\section{Targeting HbS polymerization through sickle red blood cell hydration}

Sickle RBC are naturally imperfect osmometers, ${ }^{41}$ and their biomechanical properties are dependent on RBCintrinsic properties (e.g., membrane and cytosolic contents) and RBC-extrinsic factors (e.g., environmental osmolality, surface area to volume ratio, oxygen tension). ${ }^{8}$ As such, SCD pathology results directly from the consequences of red cell dehydration, which increases $\mathrm{HbS}$ concentration within the sickle RBC, leading to polymerization under deoxygenated conditions and resultant increased cellular density and stiffness, which reduces sickle RBC deformability and increases adhesion leading to a disruption in microvascular blood flow. $5,8,42,43$ Theoretically, sickle RBC dehydration is 'targetable' and could lead to clinical improvement, but studies of agents directed at cation transport and RBC hydration mechanisms have, to date, been disappointing. While early studies suggested dipyridamole may inhibit sickling-induced cation transport and inhibit sickle RBC dehydration, ${ }^{44}$ a phase II study (NCT00276146) investigating its use was closed because of poor enrollment. A phase III, randomized, double-blind study of senicapoc (NCT00102791), a small-molecule inhibitor of $\mathrm{Ca}^{+}$-activated $\mathrm{K}^{+}$efflux (Gardos channel), reduced sickle RBC dehydration and hemolysis, ${ }^{45}$ which may be pathophysiologically important. However, the study was terminated early because of lack of improvement in vaso-occlusive event rates in adults with SCD treated with this drug in comparison to those given placebo. Early observations also found magnesium supplementation improved sickle $\mathrm{RBC}$ hydration in patients with SCD through inhibition of $\mathrm{K}-\mathrm{Cl}$ co-transport and reduction of dense sickle RBC. ${ }^{46}$ However, in the Magnesium for Children in Crisis (MAGiC) study (NCT01197417), which included young adults up to 21 years of age, when compared to the effects of placebo, intravenous magnesium did not reduce duration of stay or opioid use in patients hospitalized for vaso-occlusive events. ${ }^{47}$

\section{Other anti-sickling agents}

Allosteric modification of $\mathrm{HbS}$ from the low-oxygen affinity tense ( $\mathrm{T}$ ) state to the high-oxygen affinity relaxed (R) state reduces the risk of HbS polymer formation. ${ }^{29}$ Several novel agents manipulate this biochemical phenomenon and show promise in interrupting the molecular pathogenesis of SCD. Voxelotor (GBT440) is a small molecule that binds to the $\alpha$-globin chain in $\mathrm{HbS}$, increasing oxygen affinity to favor the $\mathrm{R}$ state. Early phase trials demonstrated that GBT440 is well-tolerated in adults with SCD and reduces morphological changes in sickle RBC. ${ }^{48,49}$ The Hemoglobin Oxygen Affinity Modulation to Inhibit $\mathrm{HbS}$ Polymerization (HOPE) study (NCT03036813) is a phase III randomized, double-blind, placebo-controlled, multicenter study evaluating the efficacy and safety of GBT440 in adolescents and adults with SCD. Early results suggest treatment with GBT440 increases hemoglobin levels in patients with SCD who have decreased markers of hemolysis when compared to patients given placebo. ${ }^{50}$ Importantly, initial evaluations did not suggest physiological oxygen deprivation with GBT440 (i.e. erythropoietin levels do not change); studies of oxygen delivery to the brain and during exercise in patients taking GBT440 are reportedly in process (unpublished, ASH 2018). AES-103 is a naturally occurring small molecule (a 5-hydroxymethyl furfural) that also binds to the $\alpha$-globin subunit in $\mathrm{HbS}$, increasing oxygen affinity and favoring the $\mathrm{R}$ state. AES103 has completed a phase I trial (NCT01597401) and was shown to be well-tolerated in a double-blind, placebocontrolled dose-escalation trial in adults with SCD. ${ }^{51}$

PEGylated bovine carboxyhemoglobin (PEG-bHb-CO; SANGUINATE ${ }^{\mathrm{TM}}$ ) is a combined oxygen transfer and carbon monoxide-releasing molecule that is given intravenously with the rationale of reducing hypoxemiainduced sickle RBC pathology. It was found to be safe and well-tolerated in a phase I trial among adults with SCD. ${ }^{52,53}$ A prospective, randomized single-dose, placebo-controlled phase II study (NCT02411708) was recently completed and interim results showed that PEG-bHb-CO administration was associated with reduced pain scores and anti-sickling properties during vaso-occlusive episodes when compared to placebo administration. ${ }^{54}$ SCD-101 is marketed as a 'botanical drug' with anti-sickling activity through an unknown mechanism and was shown in an interim analysis of a recent phase I study (NCT02380079) to be well-tolerated, and may reduce chronic pain and fatigue, improve leg ulcers, and improve sickle RBC morphology in the peripheral blood. ${ }^{5}$

The kinetics of some of the allosteric-acting agents are much faster (hours to days) than are the predominant effects of $\mathrm{HbF}$ inducers, which may take weeks to months to fully alter erythroid precursors. This difference could suggest complementary ways for using these agents.

\section{Targeting intracellular sickle red blood cell oxidative changes (antioxidant therapy)}

$\mathrm{RBC}$ are oxygen carriers, which places them in constant danger from the cumulative impact of reactive oxygen species and free radicals formed by oxygen and hemoglobin metabolism inside the RBC. ${ }^{56}$ Sickle RBC, due to their unique intracellular milieu with high concentrations of $\mathrm{HbS}$ forming and re-forming polymers, are at increased risk of oxidative damage. L-glutamine is an amino acid and a precursor used in the synthesis of glutathione and reduced nicotinamide adenine nucleotide diphosphate, which can protect the sickle RBC from oxidative damage. ${ }^{57} \mathrm{~A}$ recent multicenter, randomized, placebo-controlled, double-blind, phase III trial (NCT01179217) found that oral administration of pharmaceutical-grade L-glutamine (Endari ${ }^{\mathrm{TM}}$ ) reduced the number of vaso-occlusive events and episodes of acute chest syndrome, and hospital admissions compared to those in placebo-treated children and adults with SCD. ${ }^{58}$ In 2017 , Endari ${ }^{\mathrm{TM}}$ received orphan drug status and is FDA-approved to reduce acute compli- 
cations of SCD in patients 5 years or older. However, there remain concerns among many providers regarding the limitations of the study leading to approval for Endari $^{\mathrm{TM}}$, along with its potentially prohibitive cost, limited insurance coverage, and twice-daily powder form, which may reduce adherence. ${ }^{57,59}$ Another antioxidant agent, $\mathrm{N}$-acetylcysteine, maintains and replenishes glutathione, which is an intracellular antioxidant and scavenger of reactive oxygen species. In a phase II trial, Nacetylcysteine reduced vaso-occlusive episodes and dense sickle RBC formation. ${ }^{60}$ However, a placebo-controlled, phase III trial (NCT01849016) found N-acetylcysteine had no clinical benefit in reducing pain when given orally, albeit adherence was poor. ${ }^{61}$ Of note, $\mathrm{N}$-acetylcysteine can also reduce the formation of von Willebrand factor multimers and of von Willebrand factor-dependent platelet aggregation..$^{62}$ von Willebrand factor reactivity is high during vaso-occlusive episodes, and may sustain microvascular vaso-occlusion. ${ }^{63}$ A phase I/II trial of $\mathrm{N}$ acetylcysteine administered intravenously during vasoocclusive episodes (NCT01800526) is recruiting adult patients to determine whether this antioxidant can affect von Willebrand factor levels or function and curb pain associated with vaso-occlusion.

\section{Red blood cell extrinsic targets}

The disease-modifying approaches to SCD that target factors extrinsic to the sickle red blood cells, namely abnormal cellular adhesion and vascular dysfunction, platelet activation and hypercoagulability, and leukocytes, cytokines and other inflammatory mediators are outlined in Online Supplementary Table S2A-C, respectively, and discussed below.

\section{Targeting abnormal cellular adhesion and vascular dysfunction}

\section{Abnormal cellular adhesion}

Pioneering work in the 1980s showed that intracellular hemoglobin polymerization in SCD resulted in abnormal $\mathrm{RBC}$ adhesion to the endothelium ${ }^{64}$ This observation was soon expanded and enhanced by thoughtful investigations, and it is now recognized that many cell types, endothelial and hematopoietic, show abnormal activation and adhesion in SCD. Further, precise experimental identification of adhesive partners, such as integrins, ${ }^{65,66}$ blood group antigens, ${ }^{6}$ selectins, ${ }^{68-70}$ and white cell proteins ${ }^{71}$ have increased the repertoire of potential therapeutic targets (Online Supplementary Table S2A).

BCAM/Lu, expressed on sickle RBC, mediates adhesion to the sub-endothelial protein laminin, and this is augmented by $\beta$-adrenergic signaling. ${ }^{72}$ The effect of $\beta$-blockade by propranolol on RBC adhesion and clinical outcomes was tested in people with SCD, with suggestive but inconclusive results (NCT01077921). ${ }^{73}$

Abnormal cellular adhesion to the endothelium has been shown to be mediated by P- and E-selectins, and early work showed some benefit from an oral agent that blocked P-selectin. ${ }^{74}$ More recently, the most actively tested agents are crizanlizumab, ${ }^{75}$ which is an anti-P-selectin monoclonal antibody given prophylactically monthly, and rivipansel, which is an intravenous glycomimetic panselectin antagonist given acutely during vaso-occlusive episodes. In a randomized phase II study, crizanlizumab was tested internationally in 198 people with SCD. Compared with placebo, higher dose crizanlizumab resulted in a $45 \%$ reduction in annual crises, from $2.98 /$ year to $1.63 /$ year $(P=0.01)$. In addition, the median time to a first crisis was longer in people with SCD who were on high-dose crizanlizumab than in those on placebo (4.07 vs. 1.38 months, respectively; $P=0.001)$. Serious adverse events did not differ between patients treated with the active drug or placebo. However, normal surveillance for infection and platelet function rely on intact function of P-selectin, and this aspect will need to be monitored during more widespread use of this preventive therapy. In a phase II study, 76 people with SCD were treated with intravenous rivapansel or placebo during vaso-occlusive episodes. There were trends toward reductions in mean and median times to resolution of vaso-occlusive episodes in treated patients [ $41 \mathrm{~h}$ and $63 \mathrm{~h}$, respectively (28\% and $48 \%$ reductions in the mean and median time to resolution, respectively); $P=0.19$ for both]. These reductions were more substantial than those in the placebotreated group. A secondary endpoint, cumulative intravenous opioid use, was reduced by $83 \%$ with GMI-1070 versus placebo $(P=0.010)$. These results suggest that this agent has some efficacy during vaso-occlusive episodes. ${ }^{76}$ Both crizanlizumab (NCT03814746) and rivipansel (NCT02433158) are now undergoing phase III studies.

Intravenous immunoglobulins decrease cellular adhesion in SCD in vitro, likely due to effects on RBC-white blood cell adhesion mediated through the integrin Mac1. ${ }^{77}$ This observation formed the rationale for a phase I trial of the use of intravenous immunoglobulins in pediatric and adult patients with SCD ${ }^{78}$ while a phase II study is currently ongoing only in children (NCT01757418).

\section{Vascular dysfunction}

People with homozygous SCD experience a lifelong risk of multi-organ vasculopathy, due to the cumulative effects of hemolysis, nitric oxide depletion, inflammation and abnormal cellular adhesion. ${ }^{79}$ Therapeutic strategies including repletion of nitric oxide via inhalation have not been successful in randomized controlled studies during acute pain episodes or acute chest syndrome, ${ }^{80,81}$ but when given topically it has shown some quantitative and qualitative success in healing leg ulcers. ${ }^{82,83}$ A prospective phase II study to test topical nitric oxide as a treatment for leg ulcers is ongoing (NCT02863068).

Dietary supplementation to improve nitric oxide availability, including arginine and its precursor citrulline, has also been tried. Citrulline was studied in a small number of people with SCD, and appeared to have some benefit, ${ }^{84}$ but is not actively under study currently. Arginine has had a more robust clinical history. Thirty-eight children and young adults up to 19 years old with SCD received arginine or placebo intravenously for 5 days during a hospital admission for vaso-occlusive crisis. A significant reduction in opioid use was reported $(1.9 \pm 2.0 \mathrm{mg} / \mathrm{kg} v s .4 .1 \pm 4.1$ $\mathrm{mg} / \mathrm{kg}$, respectively; $P=0.02)$ and lower pain scores at discharge $(1.9 \pm 2.4$ vs. $3.9 \pm 2.9$, respectively; $P=0.01) .{ }^{85} \mathrm{~A}$ larger phase II study is near completion at Emory in Atlanta (NCT02536170).

Targets within the nitric oxide signaling pathway have also been identified and are being tested in clinical trials. Soluble guanylate cyclase catalyzes the production of cyclic GMP, which promotes vascular health. ${ }^{86}$ One agent, 
Riociguat $^{\circledast}$, has been shown to improve function (increased 6-minute walk distance) and decrease vascular resistance in patients with pulmonary hypertension without SCD (NCT00855465). ${ }^{87}$ The impact of this agent on pain and cardiopulmonary function is currently being tested in 100 people with SCD at multiple sites, in the SterioSCD study (NCT02633397).

As a class of drugs, 'statins' decrease systemic inflammation and improve vascular health in the general population. Twenty-five people with SCD were treated with low-dose atorvastatin for 1 month: changes were observed in cholesterol and some markers of vascular health, but no conclusive findings were made. ${ }^{88}$ In a dosefinding study, performed in 26 people with SCD over 3 weeks, simvastatin was safe and increased nitric oxide levels, while decreasing markers of inflammation (C-reactive protein and interleukin-6). ${ }^{89}$ A 3-month follow-up study in 19 people with SCD showed an excellent safety profile, an improvement in the rate but not the intensity of pain, and salutary effects on some but not all markers of inflammation and vascular health. ${ }^{90}$ This class of agents is not being actively tested at this time, but its excellent safety profile suggests that it may have a useful role in the management of selected patients with SCD.

\section{Targeting platelet activation and hypercoagulability}

SCD is a hypercoagulable state with an incidence of thromboembolism comparable to that in individuals with some inherited thrombophilias. ${ }^{12,13,91-93}$ Overactivation of hemostatic components, including platelets and coagulation factors, contributes to the vasculopathy of SCD through increased endothelial activation, platelet-leukocyte aggregates, and increased inflammation. ${ }^{13,94-96}$ As such, these factors are seen as potential targets for novel pharmaceutical interventions (Online Supplementary Table S2B).

Recent results of studies investigating antiplatelet agents targeting GPIIb/IIIa have been disappointing. A singlecenter, phase II, randomized, double-blind, placebo-controlled study (NCT00834899) found the reversible GPIIb/IIIa inhibitor eptifibatide to be safe but it did not improve time to resolution of vaso-occlusive episodes or hospital discharge. ${ }^{97}$ A secondary analysis of these data did, however, reveal that eptifibatide reduced ADP-dependent platelet aggregation, platelet-leukocyte aggregates, and inflammatory cytokines. ${ }^{98}$ Another GPIIb/IIIainhibitor, abciximab, was withdrawn from a patient-oriented study due to insufficient recruitment (NCT01932554). Prasugrel, an irreversible inhibitor of platelet aggregation through the P2Y12 class of ADP receptors has also been studied. A phase II, double-blind, randomized, multicenter trial (NCT01167023) found that prasugrel was safe, reduced markers of platelet activation including P-selectin, and was associated with a trend toward decreased pain when compared to placebo. ${ }^{99}$ While it was a negative study and patients 18 years or older were not included, the seminal phase III Determining Effects of Platelet Inhibition on VasoOcclusive Events (DOVE) trial was still informative as one of the largest multinational phase III trials in pediatric SCD and found that prasugrel did not reduce the rate of vaso-occlusive episodes in pediatric and adolescent patients up to 17 years of age when compared to placebo. ${ }^{100}$ In addition, a phase II study (HESTIA2, NCT02482298) assessing the impact of ticagrelor, a reversible P2Y12 antagonist, found that the drug was safe but did not reduce the number of diary-reported pain-free days in adults with SCD. ${ }^{101}$

While SCD is a procoagulant disorder, with chronic activation of the coagulation system through increased thrombin generation and diminished anticoagulant proteins, ${ }^{12,102}$ the clinical benefit of routine anticoagulant use in SCD is still largely unknown. For instance, warfarin, a vitamin $\mathrm{K}$ antagonist, has been associated with decreased D-dimer levels in adult patients with vaso-occlusive episodes. ${ }^{103}$ However, a recent phase II study (NCT01036802) evaluating its use in patients with pulmonary hypertension, which in some adults may be due to in-situ thrombosis formation within the pulmonary vasculature, was terminated early due to poor accrual. Similarly, a phase II feasibility study (NCT02098993) investigating unfractionated heparin in acute chest syndrome was also terminated due to poor enrollment. Interestingly, a low-molecular weight heparin, tinzaparin, shortened the durations of vaso-occlusive episodes and hospitalization compared to those in placebo-treated patients in a randomized, double-blind trial. ${ }^{104} \mathrm{~A}$ phase III study (NCT02580773) evaluating the effectiveness of tinzaparin on time to resolution of acute chest syndrome is currently recruiting participants. A randomized, doubleblind, phase II study (NCT01419977) evaluating prophylactic dosing of a low molecular weight heparin, dalteparin, during vaso-occlusive episodes has been completed and preliminary results indicate an insignificant impact on markers of coagulation, while reducing pain scores in hospitalized patients given the trial drug compared to those given placebo. ${ }^{105}$ Novel anti-Xa oral agents, too, are under investigation. A phase II study (NCT02072668) evaluating the impact of rivaroxaban on inflammatory markers during the non-crisis steady state has recently been completed. A phase III, placebo-controlled trial (NCT02179177) investigating the effect of prophylactic dosing of apixaban on daily pain scores is recruiting. Defibrotide, a sodium salt of a single-stranded polydeoxyribonucleotide with anti-thrombotic and antiinflammatory properties, is currently being evaluated primarily for safety (grade III/IV allergic reaction or hemorrhage) in a phase II study (NCT03805581) among adult patients with SCD and acute chest syndrome.

\section{Targeting leukocytes, cytokines, and other inflammatory mediators}

Patients with SCD are in a constant inflammatory state primarily due to vaso-occlusion-induced hypoxia-reperfusion, endothelial damage, and activated and aging leukocytes, in part regulated by the microbiome. ${ }^{10,106-108}$ As such, there has been a growing interest among investigators interested in targeting these inflammatory pathways for potential clinical benefit in adult patients with SCD (Online Supplementary Table S2C). Use of inhaled mometasone, a corticosteroid, is being tested in two phase II studies (NCT02061202 - IMPROVE, NCT03758950 IMPROVE2) to determine its effectiveness in reducing pain and inflammation among patients without asthma. Recent results indicate that the use of inhaled mometasone is feasible and that it can reduce circulating soluble vascular cell adhesion molecule and markers of macrophage activation, while improving daily pain scores. ${ }^{109,110}$ Invariant natural killer $\mathrm{T}$ (iNKT) cell activation is increased in patients with SCD and is regulated by the adenosine A2A receptor. ${ }^{111}$ Regadenoson, a partially selective adenosine A2A receptor 


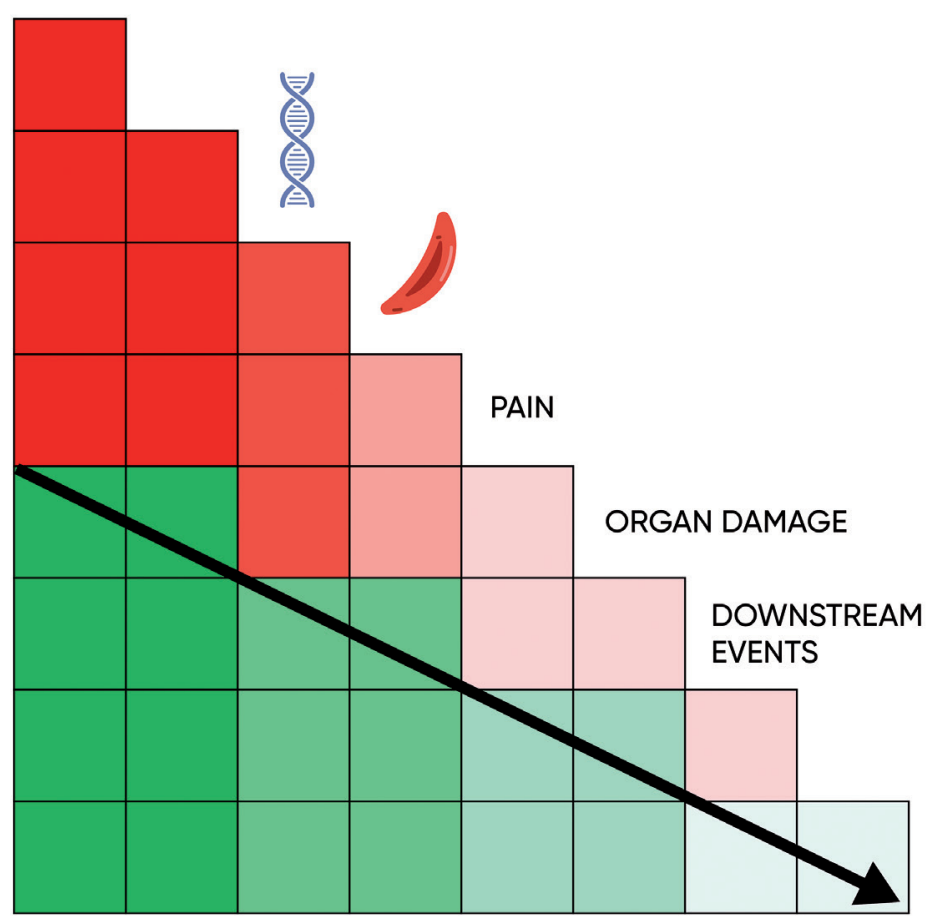

Potential for Disease Modification

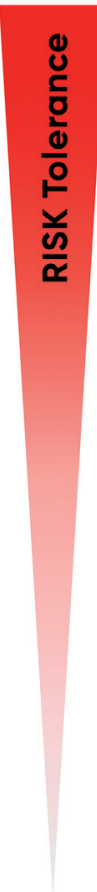

Figure 3. Risk-benefit assessments for emerging non-genetic therapies in sickle cell disease. The figure is a visual representation of risk-benefit analyses relative to the proximity of the novel therapy to red blood cell intrinsic targets, such as $\mathrm{HbF}$ or polymer formation, which are likely to have the greatest impact on disease modification (green shading). Risk tolerance (red shading) may be greater for treatments that modify disease. Downstream targets may offer significant palliation and may lengthen life, but are primarily management tools and may not warrant as great a risk. We propose a shifting level of risk tolerance (black arrow) based on the projected impact of a therapy. agonist, is a coronary vasodilator and approved by the FDA for myocardial perfusion imaging. A phase I study (NCT01085201) demonstrated that regadenoson can be safely administered to patients during vaso-occlusive episodes and reduces iNKT cell activation. ${ }^{112}$ A randomized phase II, placebo-controlled trial (NCT01788631) among patients with vaso-occlusive episodes demonstrated low-dose infusion of regadenoson did not significantly reduce iNKT cell activation, duration of hospital stay, mean total opioid use, or pain scores when compared to placebo. ${ }^{13}$ NKTT120, a humanized anti-iNKT cell monoclonal antibody, recently completed a phase I study (NCT01783691) and was found to be safe and produced rapid, sustained iNKT cell depletion in adults with SCD. ${ }^{114}$

Other novel anti-inflammatory agents are also being investigated in trials among patients with SCD. ACZ885 (canakinumab) is a monoclonal antibody that targets interleukin-1 $\beta$, a cytokine upregulated due to hemolysisinduced free heme and inflammasome activation. ${ }^{15} \mathrm{~A}$ phase II trial (NCT02961218) is recruiting adolescent and young adult patients to determine whether canakinumab can reduce daily pain scores. Leukotrienes are biologically active inflammatory mediators produced by leukocytes which are associated with SCD-related morbidity, including asthma. ${ }^{116}$ Zileuton inhibits 5-lipoxygenase, a leukotriene synthesis enzyme, and was safe and tolerable in a phase I trial (NCT01136941). ${ }^{117}$ Montelukast, a cysteinyl leukotriene receptor antagonist, is FDA-approved for the treatment of asthma. The aim of a recently com- pleted phase II study (NCT01960413) among adolescents and adults with SCD was to determine whether montelukast versus placebo added to hydroxyurea could improve markers of tissue injury associated with vasoocclusion. Results are pending. Omega-3 fatty acids may improve SCD-related pathology through reduction in vaso-occlusion-induced systemic and local inflammation. ${ }^{118}$ A phase I/II study (NCT02947100) was terminated early due to manufacturing problems. A phase III study (NCT02525107) is recruiting patients to determine whether prophylactic administration of omega-3 fatty acids can reduce the number and severity of vaso-occlusive episodes.

Lastly, intriguing research suggests that the microbiome may play a significant role in the pathology of SCD through mechanisms involving translocation of gut flora and inflammation which can affect sickle RBC and leukocytes. ${ }^{108,119}$ In a single-arm, phase II study (NCT03719729) investigators are recruiting patients with SCD to determine whether gut decontamination with rifaximin, a broad-spectrum antibiotic that inhibits bacterial RNA polymerase, is well-tolerated and can reduce admissions due to vaso-occlusive episodes.

\section{Discussion}

While stem cell and gene therapies are becoming more commonplace, they are not yet widely available to most 
patients with SCD. Therefore, optimizing non-curative approaches, i.e. those that do not involve stem cell or gene therapy, but which prevent or abort the complications of SCD, remains an important step in improving health and diminishing symptom burden in most people with SCD, in the USA and worldwide. Collaboration among the government (National Institutes of Health), industry, and academia has led to the development of a range of novel therapies that target many pathways which have been implicated in SCD-related pathophysiology. Through successful enrollment in numerous studies investigating novel therapies, it is also clear that many patients with SCD are eager to explore the potential clinical benefits of these agents. Less clear, unfortunately, are the optimal endpoints that investigators should choose when determining the beneficial role these agents may have in the clinical course and complications of SCD. Risk-benefit analyses by patients, their families, and their healthcare providers are also important. We suggest that treatments 'closer' to the proximate pathophysiological causes of SCD, such as polymer formation, may warrant greater risk exposure than do strategies that solely address downstream consequences (Figure 3), although this assessment will be fur- ther complicated when multi-modality therapies are applied. In addition, pain is such a prominent symptom and burden in SCD that its relief may warrant riskier approaches than would otherwise be considered for a single symptom or organ.

It is a time of great optimism, and in the future it may be feasible to take a multimodal approach with a combination of therapies, as seen in cancer treatment regimens, to adequately address both cause and effect in SCD. For example, agents that improve red cell health, such as Lglutamine and hydroxyurea, could be successfully combined with non-overlapping agents, such as anti-selectin therapies, which block inflammatory adhesion during painful crises. As members of the broader sickle cell community (while optimistic and enthusiastic), we must remain vigilant but reasonable, using long-term, prospective data as available to guide assessments about benefits and long-term safety of emerging treatments. We must do better in the coming years to identify complications of all novel therapies rapidly so that we can ensure that (unavoidable) risks and complications are detected, mitigated, and managed in the context of their impact on disease in order to optimize care in SCD.

\section{References}

1. Pauling L, Itano HA, et al. Sickle cell anemia a molecular disease. Science. 1949;110 (2865):543-548.

2. Piel FB, Steinberg MH, Rees DC. Sickle cell disease. N Engl J Med. 2017;377(3):305

3. Kato GJ, Piel FB, Reid CD, et al. Sickle cell disease. Nat Rev Dis Primers. 2018;4:18010.

4. Eaton WA, Hofrichter J. Hemoglobin S gelation and sickle cell disease. Blood. 1987;70(5):1245-1266.

5. Kaul DK, Fabry ME, Windisch P, Baez S, Nagel RL. Erythrocytes in sickle cell anemia are heterogeneous in their rheological and hemodynamic characteristics. J Clin Invest. 1983;72(1):22-31

6. Hebbel RP. Beyond hemoglobin polymerization: the red blood cell membrane and sickle disease pathophysiology. Blood. 1991;77(2): 214-237.

7. Kuross SA, Rank BH, Hebbel RP. Excess heme in sickle erythrocyte inside-out membranes: possible role in thiol oxidation. Blood. 1988;71(4):876-882

8. Barabino GA, Platt MO, Kaul DK. Sickle cell biomechanics. Annu Rev Biomed Eng. 2010;12:345-367

9. Bunn HF. Pathogenesis and treatment of sickle cell disease. $\mathrm{N}$ Engl J Med. 1997;337(11):762-769.

10. Zhang D, Xu C, Manwani D, Frenette PS. Neutrophils, platelets, and inflammatory pathways at the nexus of sickle cell disease pathophysiology. Blood. 2016;127(7):801809.

11. Sparkenbaugh E, Pawlinski R. Interplay between coagulation and vascular inflammation in sickle cell disease. Br J Haematol. 2013;162(1):3-14

12. Sparkenbaugh E, Pawlinski R. Prothrombotic aspects of sickle cell disease. J Thromb Haemost. 2017;15(7):1307-1316.

13. Noubouossie D, Key NS, Ataga KI. Coagulation abnormalities of sickle cell disease: relationship with clinical outcomes and the effect of disease modifying therapies. Blood Rev. 2016;30(4):245-256.

14. Platt OS, Brambilla DJ, Rosse WF, et al Mortality in sickle cell disease. Life expectancy and risk factors for early death. N Engl J Med. 1994;330(23):1639-1644.

15. Telen MJ. Beyond hydroxyurea: new and old drugs in the pipeline for sickle cell disease. Blood. 2016;127(7):810-819.

16. Moerdler S, Manwani D. New insights into the pathophysiology and development of novel therapies for sickle cell disease. Hematology Am Soc Hematol Educ Program. 2018;2018(1):493-506.

17. Kapoor S, Little JA, Pecker LH. Advances in the treatment of sickle cell disease. Mayo Clin Proc. 2018;93(12):1810-1824.

18. Hoban MD, Orkin SH, Bauer DE. Genetic treatment of a molecular disorder: gene therapy approaches to sickle cell disease. Blood. 2016;127(7):839-848.

19. Walters MC. Update of hematopoietic cell transplantation for sickle cell disease. Curr Opin Hematol. 2015;22(3):227-233.

20. Yawn BP, Buchanan GR, Afenyi-Annan AN, et al. Management of sickle cell disease: summary of the 2014 evidence-based report by expert panel members. JAMA. 2014;312(10):1033-1048.

21. Telen MJ, Malik P, Vercellotti GM Therapeutic strategies for sickle cell disease: towards a multi-agent approach. Nat Rev Drug Discov. 2019;18(2):139-158.

22. Fitzhugh CD, Abraham AA, Tisdale JF, Hsieh MM. Hematopoietic stem cell transplantation for patients with sickle cell disease: progress and future directions. Hematol Oncol Clin North Am. 2014;28(6):1171-1185.

23. Orkin SH, Bauer DE. Emerging genetic therapy for sickle cell disease. Annu Rev Med. 2019;70:257-271.

24. Morrone K, Mitchell WB, Manwani D. Novel sickle cell disease therapies: targeting pathways downstream of sickling. Semin Hematol. 2018;55(2):68-75.
25. Field JJ, Nathan DG. Advances in sickle cell therapies in the hydroxyurea era. Mol Med. 2014;20 Suppl 1:S37-42.

26. Strouse J. Sickle cell disease. Handb Clin Neurol. 2016;138:311-324.

27. Sundd P, Gladwin MT, Novelli EM Pathophysiology of sickle cell disease. Annu Rev Pathol. 2019;14:263-292.

28. Ataga KI, Desai PC. Advances in new drug therapies for the management of sickle cell disease. Expert Opin Orphan Drugs 2018;6(5):329-343.

29. Eaton WA, Bunn HF. Treating sickle cell disease by targeting $\mathrm{HbS}$ polymerization Blood. 2017;129(20):2719:2726.

30. Platt OS. Hydroxyurea for the treatment of sickle cell anemia. N Engl J Med. 2008;358(13):1362-1369.

31. McGann PT, Ware RE. Hydroxyurea therapy for sickle cell anemia. Expert Opin Drug Saf. 2015;14(11):1749-1758.

32. Paikari A, Sheehan VA. Fetal haemoglobin induction in sickle cell disease. $\mathrm{Br} \mathrm{J}$ Haematol. 2018;180(2):189-200.

33. Ginder GD. Epigenetic regulation of fetal globin gene expression in adult erythroid cells. Transl Res. 2015;165(1):115-125.

34. Molokie R, Lavelle D, Gowhari M, et al Oral tetrahydrouridine and decitabine for non-cytotoxic epigenetic gene regulation in sickle cell disease: a randomized phase 1 study. PLoS Med. 2017;14(9):e1002382.

35. Reid ME, El Beshlawy A, Inati A, et al. A double-blind, placebo-controlled phase II study of the efficacy and safety of 2,2dimethylbutyrate (HOK-1001), an oral fetal globin inducer, in sickle cell disease. Am J Hematol. 2014;89(7):709-713.

36. Bradner JE, Mak R, Tanguturi SK, et al Chemical genetic strategy identifies histone deacetylase 1 (HDAC1) and HDAC2 as therapeutic targets in sickle cell disease. Proc Natl Acad Sci U S A. 2010;107(28):1261712622.

37. Dulmovits BM, Appiah-Kubi AO, Papoin J, et al. Pomalidomide reverses gamma-globin 
silencing through the transcriptional reprogramming of adult hematopoietic progenitors. Blood. 2016;127(11):1481-1492.

38. Kutlar A, Swerdlow PS, Meiler SE, et al. Pomalidomide in sickle cell disease: phase I study of a novel anti-switching agent. Blood. 2013;122(21):777.

39. Cui S, Lim KC, Shi L, et al. The LSD1 inhibitor RN-1 induces fetal hemoglobin synthesis and reduces disease pathology in sickle cell mice. Blood. 2015;126(3):386-396.

40. Zhang Y, Paikari A, Sumazin P, et al. Metformin induces FOXO3-dependent fetal hemoglobin production in human primary erythroid cells. Blood. 2018;132(3):321-333.

41. Lew VL, Bookchin RM. Ion transport pathology in the mechanism of sickle cell dehydration. Physiol Rev. 2005;85(1):179200.

42. Nash GB, Johnson CS, Meiselman HJ. Mechanical properties of oxygenated red blood cells in sickle cell (HbSS) disease. Blood. 1984;63(1):73-82.

43. Zhou GP, Anderson KP, Joiner CH, Gallagher PG. Modification of erythrocyte hydration in the treatment of sickle cell disease. Blood Cells Mol Dis. 2001;27(1):65-68.

44. Joiner CH, Jiang M, Claussen WJ, Roszell NJ, Yasin Z, Franco RS. Dipyridamole inhibits sickling-induced cation fluxes in sickle red blood cells. Blood. 2001;97(12):3976-3983.

45. Ataga KI, Reid M, Ballas SK, et al. Improvements in haemolysis and indicators of erythrocyte survival do not correlate with acute vaso-occlusive crises in patients with sickle cell disease: a phase III randomized, placebo-controlled, double-blind study of the Gardos channel blocker senicapoc (ICA17043). Br J Haematol. 2011;153(1):92-104.

46. De Franceschi L, Bachir D, Galacteros F, et al. Oral magnesium supplements reduce erythrocyte dehydration in patients with sickle cell disease. J Clin Invest. 1997;100(7):18471852.

47. Brousseau DC, Scott JP, Badaki-Makun O, et al. A multicenter randomized controlled trial of intravenous magnesium for sickle cell pain crisis in children. Blood. 2015;126(14): 1651-1657.

48. Lehrer-Graiwer J, Howard J, Hemmaway CJ, et al. GBT440, a potent anti-sickling hemoglobin modifier reduces hemolysis, improves anemia and nearly eliminates sickle cells in peripheral blood of patients with sickle cell disease. Blood. 2015:126(23):542.

49. Howard J, Hemmaway CJ, Telfer P, et al. A phase $1 / 2$ ascending dose study and openlabel extension study of voxelotor in patients with sickle cell disease. Blood. 2019;133(17):1865-1875.

50. Vichinsky E, Hoppe C, Howard J, et al. Results from part A of the Hemoglobin Oxygen Affinity Modulation to Inhibit $\mathrm{HbS}$ Polymerization (HOPE) trial (GBT440-031), a placebo-controlled randomized study evaluating voxelotor (GBT440) in adults and adolescents with sickle cell disease. Blood. 2018;132(Suppl 1):505

51. Kato G, Lawrence MP, Mendelsohn L, et al. Phase 1 clinical trial of the candidate antisickling agent Aes-103 in adults with sickle cell anemia. Blood. 2013;122(21):1009.

52. Abuchowski A. PEGylated Bovine carboxyhemoglobin (SANGUINATE): results of clinical safety testing and use in patients. Adv Exp Med Biol. 2016;876:461-467.

53. Misra H, Bainbridge J, Berryman J, et al. A phase $\mathrm{Ib}$ open label, randomized, safety study of SANGUINATE in patients with sickle cell anemia. Rev Bras Hematol Hemoter. 2017;39(1):20-27

54. Buontempo P, Jubin RG, Buontempo C, et al.
Pegylated carboxyhemoglobin bovine (SANGUINATETM) restores RBCs roundness and reduces pain during a sickle cell vaso-occlusive crisis Blood. 2017;130(Suppl 1):969.

55. Swift R, Abdulmalik O, Chen Q, et al. SCD101: a new anti-sickling drug reduces pain and fatigue and improves red blood cell shape in peripheral blood of patients with sickle cell disease. Blood. 2016;128(22):121.

56. Jagadeeswaran R, Rivers A. Evolving treatment paradigms in sickle cell disease. Hematology Am Soc Hematol Educ Program. 2017;2017(1):440-446.

57. Quinn CT. 1-Glutamine for sickle cell anemia: more questions than answers. Blood. 2018;132(7):689-693

58. Niihara Y, Miller ST, Kanter J, et al. A phase 3 trial of l-glutamine in sickle cell disease. $\mathrm{N}$ Engl J Med. 2018;379(3):226-235.

59. Minniti CP. 1-glutamine and the dawn of combination therapy for sickle cell disease. N Engl J Med. 2018;379(3):292-294.

60. Pace BS, Shartava A, Pack-Mabien A, Mulekar M, Ardia A, Goodman SR. Effects of $\mathrm{N}$-acetylcysteine on dense cell formation in sickle cell disease. Am J Hematol. 2003;73(1):26-32.

61. Sins JWR, Fijnvandraat K, Rijneveld AW, et al. Effect of $\mathrm{N}$-acetylcysteine on pain in daily life in patients with sickle cell disease: a randomised clinical trial. $\mathrm{Br} \mathrm{J}$ Haematol. 2018;182(3):444-448.

62. Chen J, Reheman A, Gushiken FC, et al. Nacetylcysteine reduces the size and activity of von Willebrand factor in human plasma and mice. J Clin Invest. 2011:121(2):593-603.

63. Sins JWR, Schimmel M, Luken BM, et al. Dynamics of von Willebrand factor reactivity in sickle cell disease during vaso-occlusive crisis and steady state. J Thromb Haemost. 2017;15(7):1392-1402.

64. Hebbel RP, Boogaerts MA, Eaton JW, Steinberg $\mathrm{MH}$. Erythrocyte adherence to endothelium in sickle-cell anemia. A possible determinant of disease severity. N Engl J Med. 1980;302(18):992-995.

65. Takehara K, Soma Y, Igarashi A, Kikuchi K, Moro A, Ishibashi Y. Response of scleroderma fibroblasts to various growth factors. Arch Dermatol Res. 1991;283(7):461-464.

66. Chen G, Chang J, Zhang D, Pinho S, Jang JE, Frenette PS. Targeting Mac-1-mediated leukocyte-RBC interactions uncouples the benefits for acute vaso-occlusion and chronic organ damage. Exp Hematol. 2016;44(10):940-946.

67. Telen MJ. Erythrocyte adhesion receptors: blood group antigens and related molecules. Transfus Med Rev. 2005;19(1):32-44.

68. Telen MJ. Cellular adhesion and the endothelium: E-selectin, L-selectin, and panselectin inhibitors. Hematol Oncol Clin North Am. 2014:28(2):341-354

69. Okpala I. Investigational selectin-targeted therapy of sickle cell disease. Expert Opin Investig Drugs. 2015;24(2):229-238.

70. Kutlar A, Embury SH. Cellular adhesion and the endothelium: P-selectin. Hematol Oncol Clin North Am. 2014:28(2):323-339.

71. Koehl B, Nivoit P, El Nemer W, et al. The endothelin B receptor plays a crucial role in the adhesion of neutrophils to the endothelium in sickle cell disease. Haematologica. 2017;102(7):1161-1172

72. Hines PC, Zen $\mathrm{Q}$, Burney SN, et al. Novel epinephrine and cyclic AMP-mediated activation of BCAM/Lu-dependent sickle (SS) RBC adhesion. Blood. 2003;101(8):32813287

73. De Castro LM, Zennadi R, Jonassaint JC, Batchvarova M, Telen MJ. Effect of propra- nolol as antiadhesive therapy in sickle cell disease. Clin Transl Sci. 2012;5(6):437-444

74. Kutlar A, Ataga KI, McMahon L, et al. A potent oral P-selectin blocking agent improves microcirculatory blood flow and a marker of endothelial cell injury in patients with sickle cell disease. Am J Hematol. 2012;87(5):536-539.

75. Ataga KI, Kutlar A, Kanter J, et al. Crizanlizumab for the prevention of pain crises in sickle cell disease. $\mathrm{N}$ Engl J Med. 2017;376(5):429-439.

76. Telen MJ, Wun T, McCavit TL, et al Randomized phase 2 study of GMI-1070 in SCD: reduction in time to resolution of vaso-occlusive events and decreased opioid use. Blood. 2015;125(17):2656-2664

77. Jang JE, Hidalgo A, Frenette PS. Intravenous immunoglobulins modulate neutrophil activation and vascular injury through FcgammaRIII and SHP-1. Circ Res. 2012;110(8):1057-1066.

78. Manwani D, Chen G, Carullo V, et al Single-dose intravenous gammaglobulin can stabilize neutrophil Mac-1 activation in sickle cell pain crisis. Am J Hematol. 2015;90(5):381-385.

79. Kato GJ, Steinberg MH, Gladwin MT. Intravascular hemolysis and the pathophysiology of sickle cell disease. J Clin Invest. 2017;127(3):750-760

80. Maitre B, Djibre M, Katsahian S, et al Inhaled nitric oxide for acute chest syndrome in adult sickle cell patients: a randomized controlled study. Intensive Care Med. 2015;41(12):2121-2129.

81. Gladwin MT, Kato GJ, Weiner D, et al Nitric oxide for inhalation in the acute treatment of sickle cell pain crisis: a randomized controlled trial. JAMA. 2011:305(9):893-902

82. Minniti CP, Gorbach AM, Xu D, et al Topical sodium nitrite for chronic leg ulcers in patients with sickle cell anaemia: a phase 1 dose-finding safety and tolerability trial. Lancet Haematol. 2014;1(3):e95-e103.

83. Connor JL, Jr., Sclafani JA, Kato GJ, Hsieh MM, Minniti CP. Brief topical sodium nitrite and its impact on the quality of life in patients with sickle leg ulcers. Medicine (Baltimore). 2018;97(46):e12614

84. Waugh WH, Daeschner CW, 3rd, Files BA, McConnell ME, Strandjord SE. Oral citrulline as arginine precursor may be beneficial in sickle cell disease: early phase two results. J Natl Med Assoc. 2001;93(10):363371

85. Morris CR, Kuypers FA, Lavrisha L, et al. A randomized, placebo-controlled trial of arginine therapy for the treatment of children with sickle cell disease hospitalized with vaso-occlusive pain episodes Haematologica. 2013;98(9):1375-1382

86. Stasch JP, Evgenov OV. Soluble guanylate cyclase stimulators in pulmonary hypertension. Handb Exp Pharmacol. 2013;218:279313

87. Narang BK, Roy S, Sharma R, Singh V, Rawal $\mathrm{RK}$. Riociguat as a treatment regime for pulmonary arterial hypertension: a review. Clin Exp Hypertens. 2015;37(4):323-331.

88. Bereal-Williams C, Machado RF, McGowan $\mathrm{V}$ 2nd, et al. Atorvastatin reduces serum cholesterol and triglycerides with limited improvement in vascular function in adults with sickle cell anemia. Haematologica. 2012:97(11):1768-1770.

89. Hoppe C, Kuypers F, Larkin S, Hagar W, Vichinsky E, Styles L. A pilot study of the short-term use of simvastatin in sickle cell disease: effects on markers of vascular dysfunction. Br J Haematol. 2011;153(5):655663. 
